\title{
Efficiency Evaluation of Bus Transport Operations Given Exogenous Environmental Factors
}

\author{
Qiong Li, ${ }^{1}$ Peng rui Bai $\left(D^{2},{ }^{2}\right.$ Yang Chen, ${ }^{1}$ and Xiao Wei ${ }^{1}$ \\ ${ }^{1}$ College of Transportation Engineering, Chang'an University, Xi'an 710064, China \\ ${ }^{2}$ School of Management Science \& Engineering, Shanxi University of Finance and Economics, Taiyuan 030006, China \\ Correspondence should be addressed to Peng rui Bai; baipr@sxufe.edu.cn
}

Received 16 June 2020; Revised 6 September 2020; Accepted 15 September 2020; Published 29 September 2020

Academic Editor: Jinjun Tang

Copyright (c) 2020 Qiong Li et al. This is an open access article distributed under the Creative Commons Attribution License, which permits unrestricted use, distribution, and reproduction in any medium, provided the original work is properly cited.

As a mode of green transport that can effectively alleviate urban traffic congestion and improve air quality, bus transport is highly subsidized by governments at all levels in China. Thus, measuring efficiency in the bus transport sector is particularly important. However, few reports in the literature have taken exogenous environmental factors into consideration to evaluate public transport operation efficiency. This may lead to inaccurate evaluation results. This study employs the three-stage DEA model, which can eliminate the impacts of exogenous environmental factors on public bus transport operation to gain real efficiency results. Meanwhile, to further explore how exogenous environmental factors affect bus transport operations, a tobit model is used to analyse the results. The main results of this paper reveal the following: first, exogenous environmental factors have a significant impact on the operational efficiency of bus transport. It is reasonable and necessary to select the three-stage method to eliminate environmental factors for real bus operation efficiency. Second, the fluctuations of the bus transport efficiency of 30 cities decreased during 2010-2016. The western region has the highest operation efficiency, followed by the eastern and the middle regions. Third, the economic, taxi transport, and urban rail transport have a marked impact on the operational efficiency of bus transport. This paper confirms the important influence of exogenous environmental factors on the efficiency of public transport operations. In addition, this article could help improve the efficiency of urban public transport operations and promote the attractiveness of urban public transport and the amount of green travel.

\section{Introduction}

Bus transport has a major advantage over other modes of urban transit in low per capita occupancy of road resources, energy conservation, and environmental protection [1]. Serious traffic congestion and environmental pollution are threatening the sustainable development of cites all over the world [2]. The development of public bus transport is considered an effective measure to address the above urban problems [3]. Thus, efforts to expand and improve bus transport services are necessary for every city. In China, the bus transport priority policy was put forward in 2004. Since then, bus transport throughout the country was highly subsidized by governments at all levels. The increased financial support for bus transport has caused tremendous financial pressure on local governments. Given that China is a developing country, it is vital for the country to use financial resources efficiently and effectively [4]. However, it is not clear whether the function of national finance to improve bus service performance is maximized. Nonetheless, it is certain that higher efficiency in a bus transport system means more reasonable utilization of financial funds and better bus services [2]. Thus, a reliable efficiency evaluation of bus transport is extremely important.

As an important part of sustainable transport, the operation and management of public transport have been of continuous concern by scholars [5]. Most prior studies concentrated on the efficiency measurement of bus operators [6-9] and have mainly been based on desirable outputs. At the same time, many scholars have recognized the significant influencing factors on the efficiency of public bus transport operation and have constantly enriched the 
research in this field. For instance, Kang et al. [10] confirmed that a traffic accident, as an undesired output, has an important impact on the evaluation of public transport operation efficiency. Sheth et al. [11] took the consideration of environmental pollution as an uncontrolled factor to evaluate the efficiency of urban bus enterprises. Fitzová et al. [3] concluded that the uncontrollable environmental factor (population densities) was the determinant of public transport efficiency. Yao et al. [12] considered population and car ownership as exogenous environmental indicators. The performance of the public transport system was evaluated by eliminating these uncontrollable environmental variables. Meanwhile, eliminating the effects of exogenous environmental factors proved to be significant in the assessment of public transport performance. In the existing literature, only scarce research has evaluated the efficiency of public transport by taking the exogenous environment into consideration, and no research focused on the exogenous environment for an evaluation of bus transport efficiency only. It should be clearly noted that neglecting the exogenous environment may lead to unreal efficiency results. Inaccurate evaluation results will mislead the government and bus operators. To obtain information on the real efficiency of bus transport operation, it is essential to consider the exogenous environment.

Consequently, the main motivation for this research is to measure the real operational efficiency of bus transport systems in China. The contributions of this paper are as follows: (1) we select five variables as exogenous environmental factors that affect the operation of bus transport; (2) the three-stage DEA model that can eliminate the impacts of these five uncontrollable factors was employed to objectively and correctly evaluate the operation efficiency of the bus transport system; and (3) furthermore, we applied the tobit model to analyse the influence of the exogenous environment variables on operational efficiency and identify the key influencing factors. Based on empirical analysis, this paper proposes some suggestions to improve the operational efficiency of bus transport. For government agencies, the performance of bus transport will be used to measure the effects of subsidies and other priority policies. For the bus operators, performance evaluations will be beneficial for enterprises to adjust their business strategies. In addition, the academic contribution of this paper is that we found that exogenous environmental factors have an important impact on the efficiency of public transport operations. In the follow-up study, it is possible to obtain the real bus operation efficiency while the influences of exogenous environmental factors are eliminated.

The remainder of this study is structured as follows: Section 2 presents a systematic literature review of efficiency measurements of the bus transport operations. Section 3 briefly explains the research methods, input-output index system, and the exogenous environmental factors that may affect the operational efficiency. Efficiency results, the regression outcome, and the discussion are detailed in Section 4. Concluding remarks and several policy suggestions for improving the operation efficiency of bus transport are addressed in Section 5.

\section{Literature Review}

Public transport plays an important role in a city's sustainable development [2]. Consequently, public transport throughout the world is heavily subsidized by local governments [3]. In most countries, financial funds are strictly controlled. How to effectively use financial funds to support the development of public transport has become a hot issue of concern [2]. Therefore, interest in measuring the efficiency of public transport operation has been increasing. The main difference between this study and previous studies is the selection of the input-output index system and the research methods.

A well-defined input-output indicator system is the first key step to determining the accuracy of public transport efficiency evaluations [13]. Fielding et al. [14] proposed a conceptual framework to evaluate the operation performance and defined cost efficiency, service efficiency, and cost effect of the public transport system. Since then, numerous related studies by scholars have been performed based on this work. In the context of the literature on public transport efficiency evaluation, this paper makes a statistical analysis of the inputs and outputs reported in the empirical research in recent years. The following indicators are selected as inputs: employees [13-18], vehicles [14-18], fuel consumption [12-18], the length of bus lines [12, 14-21], and subsidies $[5,12,19-21]$. Compared with the input indicators, scholars have not reached an agreement on the choice of output indicators. The output indicators were mainly presented as the following: passengers [5, 12, 14-18], passenger-km $[7,18,22]$, vehicle-km $[5,21]$, and revenue [21-24].

Data envelopment analysis (DEA) is the most widely used method in the efficiency evaluation of public transport. The DEA method was initially presented by Charnes et al. [25]. As a nonparametric statistical method, DEA is an excellent empirical model that compares a decision unit with an efficient frontier using performance indicators [25]. This method has been widely accepted in urban public transport research. Fielding et al. [14] first employed this method to evaluate the operation performance of 198 bus routes in the United States. Kerstens [26] applied DEA to assess the technical efficiency of public transport companies in France. Moreover, Sun et al. [27], Chen et al. [28], and Hawas et al. [29] used DEA to analyse the performance of urban public transport. Meanwhile, the DEA method for evaluating the operational efficiency of the public transport sector is constantly improved and enriched. Starr McMullen et al. [30] adopted SMB-DEA to evaluate the efficiency of 43 public transport systems in the United States. Odeck [31] combined the DEA with Malmquist to measure changes in productivity of Norwegian bus firms. Zhang et al. [32] analysed the operational performance of urban public transport enterprises with information entropy and SE-DEA and found that the operation efficiency values of public transport fluctuate quite a bit. 
We note that, by and large, the abovementioned literature reports are largely based on the traditional DEA methods, but these methods cannot eliminate the influence of random error and external environmental factors on public transport operation efficiency. Based on the traditional DEA model, Fried et al. proposed a three-stage DEA method, which eliminates the mixture of the effective projection point and the invalid rate point, and can effectively eliminate the effect of the external environment and random error on the efficiency of a production unit, making the efficiency level results more objective and real. However, few scholars use the three-stage DEA method to study the operation efficiency of public transport, especially the bus transport operation efficiency. Yao et al. [12] took the exogenous environment into account, and their results implied that the exogenous environment had a significant effect on the operation efficiency of public transport. If the influences of the exogenous environmental factors are ignored, the efficiency result will be inaccurate. As a subsystem of the whole public transport system, the external environment of a bus transport system is different from that of the whole system. Therefore, it is necessary to study the real operational efficiency after excluding the exogenous environmental factors of a public transport system to provide a scientific decision-making basis for enterprises and governments.

Consequently, this paper attempts to fill the gap in the bus transport sector by the following research programme: (1) this study adopts information on the population, economics, taxi transport, urban rail transport, and car ownership as exogenous environmental factors that may affect bus transport operation into account and (2) the three-stage DEA model is employed to eliminate the influence of these exogenous environmental factors to obtain realistic bus transport operation efficiency values.

\section{Methodology and Data}

3.1. Three-Stage DEA Modelling Approach. Fried et al. [33] first proposed the three-stage DEA model, which mainly comprises a three-stage analysis. In the first stage, a traditional DEA model is applied to calculate the operation efficiency, which is affected by the exogenous environment, statistical noise, and management inefficiency. In the second-stage processing, the SFA method is adopted to adjust inputs by eliminating the exogenous environment and random error. In the third stage, the original outputs and the adjusted inputs from the second stage are substituted into the traditional DEA model again to determine the real efficiency. This method not only has high accuracy in the measurement of enterprise efficiency but also has been successfully used in the efficiency measurement of agricultural, logistical, cultural, and other fields. Considering the exogenous environmental factors and the applicability of the three-stage DEA model, we adopt the three-stage DEA model to evaluate the efficiency of bus transport system.

3.1.1. First Stage: Calculation of the Efficiency Value Based on the DEA Model. The DEA model is appropriate mainly for evaluating the efficiency of multiple inputs and outputs. The
DEA model mainly includes the CCR model (proposed by Charnes, Cooper, and Rhodes and named after these three scholars) [25] and the BCC model (proposed by Banker, Charnes, and Cooper and named after these three scholars) [34]. The CCR model can be used to calculate the efficiency under the condition of constant returns to scale. The BCC model was based on the CCR model and is used to evaluate the relative efficiency of the decision-making units (DMUs) with variable returns to scale. Odeck [31] noted that the BCC model is more flexible than the CCR model. In addition, the transport industry presents the characteristics of increasing returns to scale. Therefore, we employ the BCC model in this study.

The BCC model further decomposes the comprehensive efficiency into the pure technical efficiency and the scale efficiency. The comprehensive efficiency value is equal to the pure technical efficiency value multiplied by the scale efficiency value. The comprehensive efficiency is a comprehensive measurement and an evaluation of the ability of resource allocation and utilization efficiency. Pure technical efficiency measures whether the evaluation unit reaches the relative maximum output level at a certain level of science and technology input from the perspective of technology and the economy. The pure technical efficiency is determined at the system and management level. Scale efficiency refers to the gap between the existing scale and the optimal scale of the DMUs under the premise of a certain system and management level.

Before using this model, some basic hypotheses should be introduced. Assuming that the routine bus operational efficiency of $M$ cities needs to be evaluated, there are $K$ inputs and $R$ outputs in the evaluation index system. $X_{k m}$ represents the input value of the resource $m$ of the routine bus in city $k$, $y_{i r}$ denotes the output value of the type $r$ of the routine bus in city $k$. In this paper, the BCC model can be defined as follows:

$$
\begin{aligned}
& \min \left[\theta-\left(e_{1}^{T} s^{-}+e_{2}^{T} s^{+}\right)\right], \\
& \text {s.t. } \begin{cases}\sum_{k=1}^{K} x_{k m} \lambda_{i}+s^{-}=\theta x_{m}^{n}, & m=1,2, \ldots, M, \\
\sum_{k=1}^{K} y_{k r \lambda_{k}}-s^{+}=y_{r}^{n}, & r=1,2, \ldots, R, \\
\lambda_{k} \geq 0, & k=1,2, \ldots, K,\end{cases}
\end{aligned}
$$

where $\theta$ is the relative technical efficiency and $\lambda_{k}$ represents the weight of the various inputs. $S^{-}$and $S^{+}$are the slack variables of input or output, respectively. For the efficient units, their efficiency value, $\theta$, is 1 and $S^{-}=S^{+}=0$, which forms the efficient frontier.

3.1.2. Second Stage: Elimination of Exogenous Factors. According to Fried et al. [33], the influence of the exogenous environment, statistical noise, and management inefficiency are included in the efficiency results from the first stage. In the second stage, SFA regression aims to remove these effects. The SFA regressions model is set as follows: 


$$
\begin{aligned}
S_{k m}=f^{m}\left(Z_{k}, \beta^{m}\right) & +v_{k m}+u_{k m} ; \\
& m=1,2, \ldots, M ; k=1,2, \ldots, K,
\end{aligned}
$$

where $S_{k m}$ denotes the input slacks, which are influenced by the environmental effects, statistical noise, and managerial inefficiency. $f^{m}\left(Z_{k}, \beta^{m}\right)$ represents the effects of the exogenous environmental variables on the slack variables. $Z_{k}$ represents the environmental effects that are likely to influence the efficiency of the routine bus system, and $\beta^{m}$ denotes a parameter vector to be estimated. $v_{k m}+u_{k m}$ is the hybrid error, $v_{i m}$ represents the random interference obeying a $N\left(0, \sigma_{v}^{2}\right)$ distribution, and $u_{k m}$ denotes the managerial inefficiency. $v_{k m}$ and $u_{k m}$ are independent and irrelevant.

In addition, for the purpose of measuring the impact of random interference, we should separate random disturbances from the management inefficiency. In the process of eliminating random interference, we choose the estimated values $\left(\widehat{\beta^{m}}, \widehat{u^{m}}, \widehat{\sigma_{k m}^{2}}, \widehat{\sigma_{k m}^{2}}\right)$ that result from the SFA model regression analysis and the conditional nondeviation estimation, $\widehat{E}\left[v_{k m} /\left(v_{k m}+u_{k m}\right)\right]$. The method is as follows:

$$
\begin{aligned}
\widehat{E}\left[\frac{v_{k m}}{v_{k m}+u_{k m}}\right]=S_{k m}-Z_{k} \widehat{\beta}^{m}-\widehat{\widehat{E}}\left[\frac{v_{k m}}{v_{k m}+u_{k m}}\right], \\
k=1, \ldots, K ; m=1, \ldots, M .
\end{aligned}
$$

To eliminate the effects of the random factors and exogenous factors, the original inputs should be adjusted. All the DMUs are in the same environment after adjustment. In other words, the DMUs must be adjusted in poor environments. These can be described as shown in the following equation:

$$
\begin{gathered}
\widehat{\chi_{k m}}=\chi_{k m}+\left[\max _{m}\left(Z_{k} \widehat{\beta^{m}}\right)-Z_{k} \widehat{\beta^{m}}\right]+\left[\max \left(\widehat{v_{k m}}\right)-\widehat{v_{k m}}\right], \\
k=1, \ldots, K ; m=1, \ldots, M,
\end{gathered}
$$

where $\widehat{\chi_{k m}}$ and $\chi_{k m}$, respectively, represent the adjusted inputs and original inputs. The term $\max _{m}\left(Z_{k} \widehat{\beta^{m}}\right)-Z_{k} \widehat{\beta^{m}}$ represents the adjustment to place all DMUs in the same environment, while $\max \left(\widehat{v_{k m}}\right)-v_{k m}$ denotes the adjustment that places all of the DMUs in a common state of nature. The above adjustment enables all of the DMUs to confront the same external environment and operational luck [35].

3.1.3. Third Stage: Measurement of Real Efficiency. The BCC model is employed again to obtain the final operation efficiency of the bus transport system by using the initial outputs and the adjusted inputs. Excluding the impacts of the environmental effects, statistical noise, and managerial inefficiency, the final measurement would then be a more realistic reflection of the real level of operational efficiency of bus transport.

3.2. Tobit Model. To further explore how the exogenous environmental factors affect the bus transport operation, we employ a tobit model, which was first proposed by Tobin
[36], for the analysis. The tobit model has been widely used in the fields of management science and operations research to the investigate the factors that affect efficiency, thus indicating that the tobit model is an effective method to analyse the influence of factors [37]. Thus, we employ a tobit model to measure the impact of the exogenous environmental factors on the operational efficiency of bus transport. The tobit model can be described as follows:

$$
\begin{aligned}
E_{i}^{*} & =\beta X_{j}+\varepsilon_{i}, \quad j=1,2, \ldots, K, \\
E_{i} & =E_{i}^{*}, \quad \text { if } Y_{i}^{*}>0, \\
E_{i} & =0, \quad \text { if } Y_{i}^{*} \leq 0,
\end{aligned}
$$

where $E_{i}$ is the dependent variable; $\beta$ is a vector of the calculated parameters; $\varepsilon_{i}$ is an independent, normal error term with a constant variance, $\sigma^{2}$, and 0 mean value; $K$ is the sample size; and $X_{j}$ is a vector of explanatory variables [38].

3.3. Variable Selection. This paper is based on the principle of high-quality data selection. The following section details the variables (input-output and external environment) and the data sources used for measuring urban bus operational efficiency.

3.3.1. Input-Output Variables. The operation of the bus transport system is a complex process involving local governments, bus transport operators, and passengers [12]. Financial subsidies of bus transport are mainly presented as subsidies for the fare, vehicle purchases, station construction, fuel consumption, and various tax preferences. The government's financial subsidies are fed back to bus transport operators and passengers in different forms. From the perspective of bus transport operators, subsidies can be mainly reflected by the number of vehicles, fuel consumption, line operating mileage, and the number of passenger trips completed. For passengers, they can decide voluntarily whether to enjoy a certain level of bus transport service at a lower fare. Furthermore, the number of passengers represents, to some extent, the service quality of public transport provided by enterprises.

Different input-output index systems lead to different efficiency results for the same evaluation objective. Therefore, the selection of the input-output index is the first critical step in the measurement of efficiency [39]. To measure the operation efficiency of bus transport through the three-stage DEA model, we should first select reasonable input-output variables.

According to information found in the literature review, most of the existing studies take five indicators (employees, vehicles, fuel consumption, the length of bus lines, and subsidies) as inputs of public transport operation efficiency. However, not every city has officially published the annual fuel consumption data of its bus transport. In fact, vehicle operating mileage is approximately proportional to energy consumption. Consequently, we select the vehicle operating mileage to express fuel input. In theory, subsidies can best describe the government's investment in the bus transport. However, in practical terms, subsidies data of bus transport 
is not typically disclosed. Considering the limitation of the sample size, the subsidy is not included in the input index in this study. In summary, we select employees, vehicles, and operating mileage as the input indicators.

Regarding output related to bus transport service, the variables commonly used in the previous analysis are vehicle$\mathrm{km}$, passenger- $\mathrm{km}$, revenue, and passengers. However, the vehicle-km mainly reflects the vehicle operating mileage. The operation of a vehicle does not necessarily mean an increase in the operating income, but it is certain that there must be fuel consumption. Therefore, this paper does not consider vehicle$\mathrm{km}$ as an indicator of output. Based on China's bus cardswiping system, we can only obtain the number of passengers, but not the distance they travel. Therefore, compared with the passenger-km, passenger volume can more accurately represent the effective output of the bus transport system. To obtain more government subsidies, bus transport operators are reluctant to disclose their real ticket revenue. Thus, it is impossible to use ticket revenue as an output in this paper. Accordingly, considering the maximization of service output, this paper selects passenger volume as the output variable to illustrate the attraction of bus transport. The data of the above four input and output variables are collected from the China Transport Statistical Yearbooks. The descriptive statistics of these indicators are provided in Table 1.

3.3.2. Exogenous Environmental Variables. As a main mode of public transport, bus transport can meet the travel needs of the vast majority with a low cost. Thus, the evaluation of a bus transport's service efficiency is particularly important for the development of bus transport. However, the efficiency of bus transport may be significantly affected by exogenous environmental factors $[10,12,40]$. It is essential to choose reasonable exogenous environmental factors for further analysis. Exogenous environmental variables refer to the external factors that are not controlled by the bus operators and have an impact on the service efficiency of the bus system. According to the identification principle of exogenous factors employed in other industries $[35,39,41]$ and fully combining them with the bus transport operational environment, this paper proposes five variables that may have an impact on operational efficiency.

(1) Population Density. Population size is an important factor to determine the total travel volume of urban residents. A larger population may mean a greater total number and frequency of public transport trips. Furthermore, the city scale plays a significant role in the travel distance and travel frequency. Thus, we assume that population density, which is expressed by the ratio of the population (the sum of urban resident population and temporary urban population) to urban buildup area, is one of the factors influencing the operational efficiency of bus transport. The coefficient of the population density is predicted to be positive [12].

(2) GDP per Capita. According to international practice, it is reasonable that the travel cost accounts for less than $10 \%$ of the income cost. We can conclude that the level of income is
TABLE 1: Descriptive statistics of input-output indicators.

\begin{tabular}{lcccc}
\hline Attributes & Max & Min & Mean & SE \\
\hline Passenger volume $\left(10^{4}\right)$ & 503272 & 19921 & 119764.4 & 85884.61 \\
Operation mileage $\left(10^{4} \mathrm{~km}\right)$ & 135624 & 6662 & 43526.7 & 32234.6 \\
Number of vehicles & 36572 & 1398 & 8899.74 & 6707.48 \\
Number of employees & 88115 & 2744 & 6707.48 & 17858.18 \\
\hline
\end{tabular}

one of the key factors affecting the choice of travel mode. People with a high income may pay more attention to the comfort and convenience of the travel mode than the travel cost. In contrast, the low-income group is more concerned about the travel cost. Therefore, we expect income to be a factor in bus transport efficiency. In this study, the city's income level is represented by the GDP per capita of the city. The coefficient of the GDP per capita of a city is predicted to be negative.

(3) Taxi Transport. Due to mobility, flexibility, and convenience, taxi transport greatly meets the high-quality and personalized travel needs of the public. According to the Statistics Bulletin of Transport Industry Development in China, in recent years, the passenger volume completed by taxi transport accounts for approximately $30 \%$ of the total passenger volume of public transport. This means that taxi transport is an important mode of public transport. With continuous improvements in income levels, the influence of taxi transport on the bus transport system cannot be ignored. Based on the reliability of the statistical data, this paper selects the number of taxis as one of the environmental variables. Its effect is expected to be negative.

(4) Urban Rail Transport. Urban rail transport has incomparable advantages over bus transport in terms of punctuality, rapidity, and large traffic capacity, which enables urban rail transport to be much more attractive than bus transport. Experience shows that the passenger volume of bus transport faces a continuous decline after the urban rail transport has been put into operation. The above suggests that urban rail transport has a significant impact on the bus system. In this paper, the passenger volume of urban rail transport is adopted to measure this effect. The coefficient of the passenger volume of urban rail transport is predicted to be negative.

(5) Car Ownership. With the continuous improvement of people's lives, more and more cars are purchased by Chinese people. A private car brings a much greater degree of comfort and convenience and a strong sense of superiority to the owner. Because of this, people generally prefer to commute and travel by car instead of using the bus transport system. Consequently, car owners rarely choose to travel by bus [42]. Therefore, car ownership is considered to be a significant element that influences bus transport operation efficiency, and its coefficient is predicted to be negative [12].

The data of these exogenous variables are derived from The Yearbook of China's Cities, China Transport Statistics Yearbooks and China Urban Construction Statistical Yearbooks. The development of urban rail transit systems in 
China is extremely unbalanced. With more and more cities operating urban rail transport in recent years, the imbalance is gradually shrinking. To accurately evaluate the impact of urban rail transport on bus transport operation, 2010-2016 is set as the time span of this study. Unfortunately, due to lack of data, Lhasa, Fuzhou, Shijiazhuang, Lanzhou, Xining, and Xiamen were not included in this study. We ultimately collected data from the other 30 central cities during 2010-2016. The descriptive statistics of the exogenous variables are listed in Table 2.

\section{Results and Discussion}

4.1. First Stage: Analysis of the Traditional DEA Results. In the first stage, the operational efficiency of bus transport of 30 central cities from 2010 to 2016 are evaluated using a BCC model, as illustrated in Table 3 . The average operation efficiency of bus transport in these 30 central cities is 0.844 . In terms of the time series, the average efficiency values of the nationwide and eastern and middle region groups all present drops in their fluctuations. In contrast, the efficiency value of the western region shows an increasing tendency of fluctuations, and they are higher than those of the other two regions. The average of pure technical efficiency values is 0.905, and all three regions show a slight decline from 2010 to 2016. There is no significant difference between the eastern and the middle regions, while the western region is obviously higher than the other two. The mean scale efficiency value of the 30 cities is 0.932 from 2010 to 2016 . The average values of the eastern and the middle regions from 2010 to 2016 showed a downward trend in their fluctuations, and the differences and change ranges were small, while the mean value of western region fluctuates upward. The average scale efficiency value is significantly higher than the average of the pure technical efficiency value, indicating that the main factor limiting the improvement of the operation efficiency is the low pure technical efficiency. However, this result does not exclude environmental and random factors. To obtain the real operation efficiency, further adjustments and calculations are needed.

4.2. Second Stage: Elimination of the Environmental Effects. First, to avoid inaccurate regression caused by different data units, the five exogenous variables were standardized. Then, the SFA method is employed to analyse the 3 input slack variables. Five external variables, including population density, number of taxis, passenger volume of urban rail transport, GDP per capita, and car ownership, are used as the independent variables of the slack variables. Table 4 presents the regression results of the input slack variables and the five environmental variables.

As shown in Table 4, most of the five environmental variables pass the $1 \%$ significance level test, and the LR test value of the one-sided error is under the $1 \%$ significance level, implying the rationality of the selected model. The $\gamma$ value of the five environmental variables are all close to 1 , indicating that the influence of these external factors is more significant than that of statistical noise [35]. In
TABLE 2: Descriptive statistics of exogenous variables.

\begin{tabular}{lcccc}
\hline Attributes & Max & Mini & Mean & SE \\
\hline Population density & 2.42 & 0.67 & 1.03 & 0.34 \\
GDP per capita & 57275 & 29502 & 39087.13 & 8806.85 \\
Number of taxis & 66646 & 2352 & 14038 & 13664.34 \\
Passenger volume of rail & 377801 & 0 & 59467.17 & 102305.83 \\
transit & 452.8 & 56.29 & 171.31 & 92.55 \\
Car ownership & & & & \\
\hline
\end{tabular}

conclusion, the results show that it is quite necessary to remove the effects of exogenous factors by using the SFA model.

According to previous literature reports $[33,35,39,41,43]$, the exogenous indicators with a negative coefficient are favourable to efficiency improvement. In other words, an increase in the value of the exogenous variable will lead to a decrease in the input waste. Conversely, the exogenous indicators with positive coefficient have a negative effect on operation efficiency. That is, an increase in the value of the coefficient of an environmental variable will generate more input slack.

4.3. Third Stage: Analysis of Real Operation Efficiency. Table 5 presents the real operation efficiency of bus transport (eliminating the influences of environmental effects, managerial inefficiencies, and statistical noise) of the 30 central cities in China. As revealed in Table 5, the average operation efficiency of the 30 central cities is 0.836 . Nine cities, namely, Beijing, Shenyang, Dalian, Xiamen, Harbin, Chongqing, Chengdu, Guiyang, and Xi'an, had values higher than 0.9, accounting for $30 \%$ of the cities. In terms of the time series, the average comprehensive efficiency (the real operation efficiency) value of the 30 cities decreased from 0.854 in 2010 to 0.801 in 2016. Regionally, the western region had the highest operation efficiency during 2010-2016, followed by the eastern and the middle regions, as shown in Figure 1. Since the eastern and middle regions are more developed, the travel choices of people are less constrained by travel cost, and they prefer to choose more convenient and faster traffic modes. Additionally, the more developed urban rail transport and higher car ownership values provide more travel options for people. Therefore, the utilization of bus transport with relatively poor service quality is not as high. In contrast, due to the less developed economy, bus transport is the dominant travel mode for the vast majority. The service improvement of bus transport brought by the large-scale government subsidies increased its attraction to passengers.

As indicated in Figure 2, the average values of scale efficiency (SE) are always higher than that of the pure technical efficiency (PTE), and the fluctuation trend of the operation efficiency is the same as that of the scale efficiency. This indicated that the main factor determining the operational efficiency of bus transport is the pure technical efficiency. In other words, the operational efficiency (TE) of bus transport is largely limited by the pure technical efficiency. 
TABLE 3: Bus transport operation efficiency of 30 central cities in China, 2010-2016.

\begin{tabular}{|c|c|c|c|c|c|c|c|c|c|c|c|c|}
\hline \multirow{2}{*}{$\begin{array}{l}\text { Year } \\
\text { DMU }\end{array}$} & \multicolumn{3}{|c|}{2010} & \multicolumn{3}{|c|}{2012} & \multicolumn{3}{|c|}{2014} & \multicolumn{3}{|c|}{2016} \\
\hline & $\mathrm{TE}$ & PTE & SE & $\mathrm{TE}$ & PTE & SE & $\mathrm{TE}$ & PTE & SE & $\mathrm{TE}$ & PTE & SE \\
\hline Eastern average & 0.812 & 0.886 & 0.912 & 0.774 & 0.896 & 0.861 & 0.832 & 0.884 & 0.940 & 0.773 & 0.865 & 0.895 \\
\hline Beijing & 0.842 & 1.000 & 0.842 & 0.801 & 1.000 & 0.801 & 0.770 & 1.000 & 0.770 & 0.695 & 1.000 & 0.695 \\
\hline Tianjin & 0.741 & 0.788 & 0.940 & 0.819 & 0.904 & 0.907 & 0.907 & 0.944 & 0.960 & 0.811 & 0.915 & 0.886 \\
\hline Shenyang & 0.971 & 1.000 & 0.971 & 0.867 & 0.940 & 0.922 & 0.919 & 0.932 & 0.986 & 1.000 & 1.000 & 1.000 \\
\hline Shanghai & 0.647 & 0.822 & 0.788 & 0.607 & 0.839 & 0.723 & 0.707 & 0.838 & 0.844 & 0.642 & 0.796 & 0.806 \\
\hline Nanjing & 0.631 & 0.673 & 0.936 & 0.571 & 0.663 & 0.861 & 0.579 & 0.591 & 0.979 & 0.526 & 0.537 & 0.981 \\
\hline Hangzhou & 0.677 & 0.740 & 0.915 & 0.672 & 0.798 & 0.843 & 0.806 & 0.825 & 0.977 & 0.839 & 0.840 & 1.000 \\
\hline Jinan & 0.989 & 1.000 & 0.989 & 0.874 & 0.930 & 0.940 & 0.865 & 0.867 & 0.998 & 0.820 & 0.845 & 0.969 \\
\hline Guangzhou & 0.974 & 1.000 & 0.974 & 0.772 & 0.989 & 0.780 & 0.906 & 1.000 & 0.906 & 0.791 & 0.914 & 0.866 \\
\hline Haikou & 0.825 & 1.000 & 0.825 & 0.827 & 1.000 & 0.827 & 1.000 & 1.000 & 1.000 & 0.696 & 1.000 & 0.696 \\
\hline Dalian & 0.917 & 0.984 & 0.932 & 0.920 & 0.989 & 0.930 & 1.000 & 1.000 & 1.000 & 1.000 & 1.000 & 1.000 \\
\hline Qingdao & 0.792 & 0.836 & 0.947 & 0.740 & 0.828 & 0.894 & 0.743 & 0.774 & 0.959 & 0.754 & 0.791 & 0.953 \\
\hline Xiamen & 1.000 & 1.000 & 1.000 & 1.000 & 1.000 & 1.000 & 1.000 & 1.000 & 1.000 & 1.000 & 1.000 & 1.000 \\
\hline Shenzhen & 0.544 & 0.678 & 0.803 & 0.588 & 0.773 & 0.761 & 0.611 & 0.724 & 0.844 & 0.474 & 0.601 & 0.789 \\
\hline Central average & 0.853 & 0.877 & 0.972 & 0.829 & 0.882 & 0.941 & 0.866 & 0.874 & 0.991 & 0.817 & 0.845 & 0.968 \\
\hline Taiyuan & 0.891 & 0.894 & 0.997 & 0.965 & 1.000 & 0.965 & 0.987 & 1.000 & 0.987 & 0.914 & 0.919 & 0.994 \\
\hline Changchun & 0.798 & 0.801 & 0.996 & 0.831 & 0.835 & 0.995 & 0.806 & 0.808 & 0.998 & 0.912 & 0.970 & 0.940 \\
\hline Harbin & 0.800 & 0.851 & 0.940 & 0.796 & 0.907 & 0.878 & 0.991 & 1.000 & 0.991 & 0.974 & 1.000 & 0.974 \\
\hline Hefei & 0.851 & 0.859 & 0.991 & 0.809 & 0.814 & 0.994 & 0.789 & 0.802 & 0.984 & 0.719 & 0.741 & 0.971 \\
\hline Nanchang & 0.948 & 1.000 & 0.948 & 0.939 & 1.000 & 0.939 & 1.000 & 1.000 & 1.000 & 0.701 & 0.767 & 0.914 \\
\hline Zhengzhou & 1.000 & 1.000 & 1.000 & 0.886 & 0.927 & 0.956 & 0.875 & 0.875 & 1.000 & 0.829 & 0.833 & 0.995 \\
\hline Wuhan & 0.691 & 0.759 & 0.910 & 0.682 & 0.823 & 0.829 & 0.815 & 0.824 & 0.990 & 0.833 & 0.870 & 0.957 \\
\hline Changsha & 0.847 & 0.855 & 0.991 & 0.725 & 0.749 & 0.968 & 0.668 & 0.685 & 0.975 & 0.655 & 0.656 & 0.999 \\
\hline Western average & 0.924 & 0.993 & 0.931 & 0.856 & 0.975 & 0.880 & 0.918 & 0.943 & 0.975 & 0.950 & 0.962 & 0.994 \\
\hline Huhehot & 0.920 & 1.000 & 0.920 & 0.717 & 1.000 & 0.717 & 0.869 & 1.000 & 0.869 & 1.000 & 1.000 & 0.987 \\
\hline Nanning & 1.000 & 1.000 & 1.000 & 0.894 & 1.000 & 0.894 & 0.787 & 0.798 & 0.986 & 1.000 & 1.000 & 1.000 \\
\hline Chongqing & 0.957 & 1.000 & 0.957 & 0.870 & 1.000 & 0.870 & 1.000 & 1.000 & 1.000 & 1.000 & 1.000 & 1.000 \\
\hline Chengdu & 0.904 & 1.000 & 0.904 & 0.972 & 1.000 & 0.972 & 0.999 & 1.000 & 0.999 & 1.000 & 1.000 & 1.000 \\
\hline Guiyang & 1.000 & 1.000 & 1.000 & 1.000 & 1.000 & 1.000 & 1.000 & 1.000 & 1.000 & 0.951 & 0.955 & 1.000 \\
\hline Kunming & 0.919 & 0.933 & 0.986 & 0.783 & 0.825 & 0.949 & 0.781 & 0.793 & 0.985 & 0.807 & 0.814 & 0.996 \\
\hline Xi'an & 0.938 & 1.000 & 0.938 & 0.852 & 1.000 & 0.852 & 1.000 & 1.000 & 1.000 & 0.915 & 0.927 & 0.992 \\
\hline Yinchuan & 0.678 & 1.000 & 0.678 & 0.705 & 1.000 & 0.705 & 0.932 & 1.000 & 0.932 & 0.916 & 1.000 & 0.987 \\
\hline Urumqi & 0.999 & 1.000 & 0.999 & 0.915 & 0.954 & 0.958 & 0.897 & 0.897 & 1.000 & 0.957 & 0.963 & 0.916 \\
\hline Mean & 0.856 & 0.916 & 0.934 & 0.813 & 0.916 & 0.888 & 0.867 & 0.899 & 0.964 & 0.838 & 0.888 & 0.942 \\
\hline
\end{tabular}

TABLE 4: SFA model parameters and estimation results.

\begin{tabular}{lccc}
\hline Slacks & Operating mileage & Number of vehicles & Annual employees \\
\hline Constant term & $-4049.108^{* * *}(-4037.919)$ & $-188.7556^{* * *}(-188.7675)$ & $-3595.1267^{* * *}(-3594.9366)$ \\
Population density & $-1341.328^{* * *}(-1336.227)$ & $-79.0747^{* * *}(-79.0833)$ & $258.5492^{* * *}(258.5331)$ \\
Number of taxis & $-0.013(-0.214)$ & $-0.0024(-1.1804)$ & $0.0407^{* * *}(3.9024)$ \\
Passenger volume of rail transport & $-0.001(-0.324)$ & $-0.0005(-1.2203)$ & $-0.0041^{*}(-1.7184)$ \\
GDP per capita & $0.033^{* * *}(7.260)$ & $0.0004(1.5088)$ & $0.0223^{* * *}(3.5629)$ \\
Car ownership & $7.116^{* * *}(6.768)$ & $1.0107^{* * *}(26.3293)$ & $-0.9459(-0.5920)$ \\
Sigma-squared & 12664230.000 & 246133.040 & 4847562.800 \\
Gamma & 0.999 & 0.999 & 1.0000 \\
Log likelihood & -264.729 & -203.605 & -254.583 \\
LR test of the one-side error & $21.224^{* * *}$ & $22.486^{* * *}$ & $13.576^{* * *}$ \\
\hline
\end{tabular}

${ }^{*} P<0.05^{; * *} P<0.01$ 1*** $P<0.001$. The value of $T$ is in brackets.

4.4. Comparison of the First-Stage and the Third-Stage Efficiency Values. Figure 3 shows the changes of the average comprehensive technical efficiency values of bus transport during 2010-2016 before and after the adjustment. This figure shows that the values of 15 cities increased, while those of 15 cities decreased slightly. Through comparison and analysis, after external environmental factors were eliminated, the cities with improved efficiency were basically related to the operation of rail transit. Further study found that the higher the operating mileage of urban rail transit was, the greater the efficiency improved. For example, Shanghai and Beijing, which have the largest and secondlargest rail transit lines, respectively, also have the top two efficiency growth rates. In the 15 cities with declining 
TABLE 5: Comparison between the results of the first stage and the third stage.

\begin{tabular}{|c|c|c|c|c|c|c|}
\hline \multirow{2}{*}{ City } & \multicolumn{2}{|c|}{ Average TE } & \multicolumn{2}{|c|}{ Average PTE } & \multicolumn{2}{|c|}{ Average SE } \\
\hline & First stage & Third stage & First stage & Third stage & First stage & Third stage \\
\hline Eastern region average & 0.797 & 0.823 & 0.883 & 0.887 & 0.902 & 0.931 \\
\hline Beijing & 0.777 & 0.920 & 1.000 & 1.000 & 0.777 & 0.920 \\
\hline Tianjin & 0.820 & 0.865 & 0.888 & 0.878 & 0.923 & 0.987 \\
\hline Shenyang & 0.939 & 0.944 & 0.968 & 0.948 & 0.970 & 0.996 \\
\hline Shanghai & 0.651 & 0.758 & 0.824 & 0.827 & 0.790 & 0.917 \\
\hline Nanjing & 0.577 & 0.631 & 0.616 & 0.640 & 0.939 & 0.986 \\
\hline Hangzhou & 0.749 & 0.802 & 0.801 & 0.816 & 0.934 & 0.983 \\
\hline Jinan & 0.887 & 0.855 & 0.911 & 0.898 & 0.974 & 0.955 \\
\hline Guangzhou & 0.861 & 0.894 & 0.976 & 0.975 & 0.882 & 0.916 \\
\hline Haikou & 0.837 & 0.672 & 1.000 & 1.000 & 0.837 & 0.672 \\
\hline Dalian & 0.959 & 0.985 & 0.993 & 1.000 & 0.966 & 0.985 \\
\hline Qingdao & 0.757 & 0.802 & 0.807 & 0.856 & 0.938 & 0.941 \\
\hline Xiamen & 1.000 & 0.952 & 1.000 & 1.000 & 1.000 & 0.952 \\
\hline Shenzhen & 0.554 & 0.620 & 0.694 & 0.696 & 0.799 & 0.891 \\
\hline Central region average & 0.841 & 0.817 & 0.870 & 0.875 & 0.968 & 0.936 \\
\hline Taiyuan & 0.939 & 0.837 & 0.953 & 0.928 & 0.986 & 0.901 \\
\hline Changchun & 0.837 & 0.802 & 0.854 & 0.860 & 0.982 & 0.936 \\
\hline Harbin & 0.890 & 0.927 & 0.940 & 0.927 & 0.946 & 1.000 \\
\hline Hefei & 0.792 & 0.764 & 0.804 & 0.814 & 0.985 & 0.939 \\
\hline Nanchang & 0.897 & 0.770 & 0.942 & 0.970 & 0.950 & 0.790 \\
\hline Zhengzhou & 0.898 & 0.855 & 0.909 & 0.872 & 0.988 & 0.983 \\
\hline Wuhan & 0.755 & 0.823 & 0.819 & 0.845 & 0.922 & 0.974 \\
\hline Changsha & 0.724 & 0.757 & 0.736 & 0.783 & 0.983 & 0.966 \\
\hline Western region average & 0.912 & 0.872 & 0.968 & 0.954 & 0.943 & 0.917 \\
\hline Huhhot & 0.877 & 0.817 & 1.000 & 1.000 & 0.877 & 0.817 \\
\hline Nanning & 0.920 & 0.812 & 0.950 & 0.922 & 0.970 & 0.880 \\
\hline Chongqing & 0.957 & 1.000 & 1.000 & 1.000 & 0.957 & 1.000 \\
\hline Chengdu & 0.969 & 0.978 & 1.000 & 0.988 & 0.969 & 0.990 \\
\hline Guiyang & 0.988 & 0.932 & 0.989 & 0.972 & 0.999 & 0.958 \\
\hline Kunming & 0.823 & 0.786 & 0.841 & 0.792 & 0.978 & 0.992 \\
\hline Xi'an & 0.926 & 0.977 & 0.982 & 0.978 & 0.944 & 0.999 \\
\hline Yinchuan & 0.808 & 0.671 & 1.000 & 1.000 & 0.808 & 0.671 \\
\hline Urumqi & 0.942 & 0.881 & 0.954 & 0.930 & 0.988 & 0.950 \\
\hline National average & 0.844 & 0.836 & 0.905 & 0.904 & 0.932 & 0.928 \\
\hline
\end{tabular}

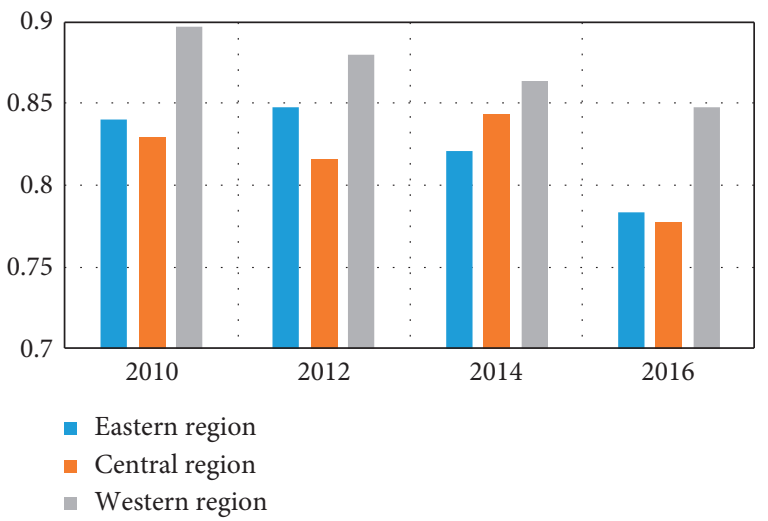

FIGURE 1: Changes of the operation efficiency in the three regions of China (2010-2016).

efficiency, either there was no operating rail transit or the lengths of the rail transit were particularly short. This is further verification that urban rail transit has an important impact on bus transport operations. Figure 4 shows that the

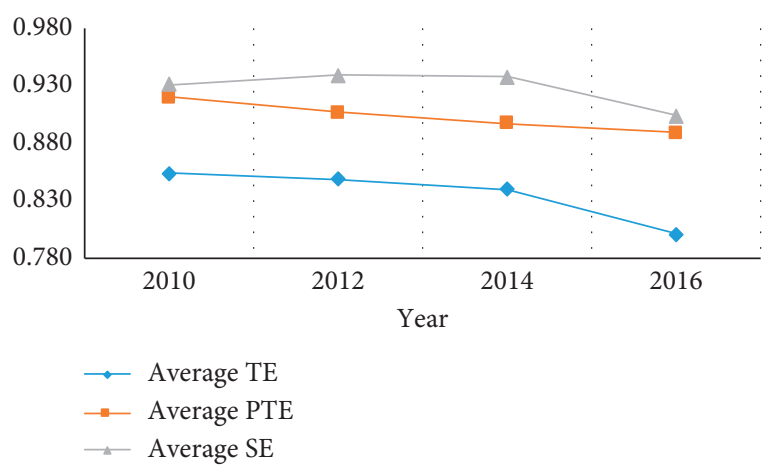

Figure 2: China's average operation efficiency of bus transport.

average pure technology efficiency value of each city has not changed very much before and after adjustment. However, it can be seen that the scale efficiency value has changed significantly in Figure 5. Among them, 16 cities achieved growth, and the top two cities were Beijing and Shanghai, while 14 cities declined, and the two cities with the greatest declining values were Haikou and Nanchang. 


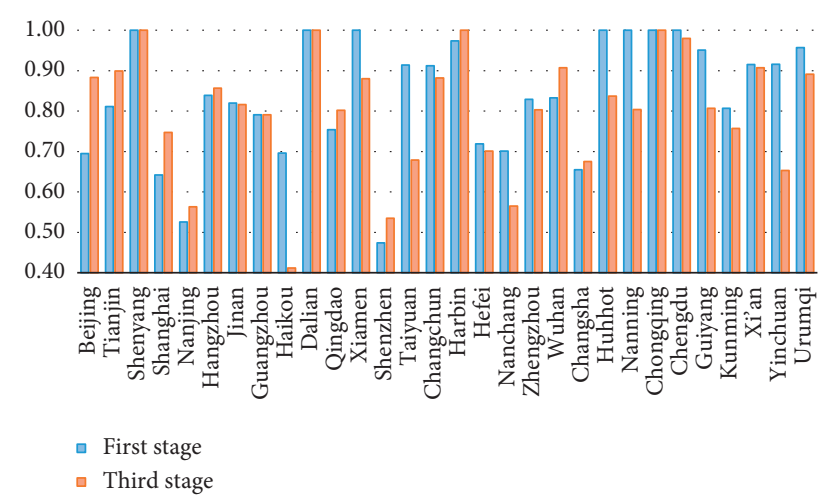

Figure 3: Comparison of average operation efficiency before and after adjustment (2010-2016).

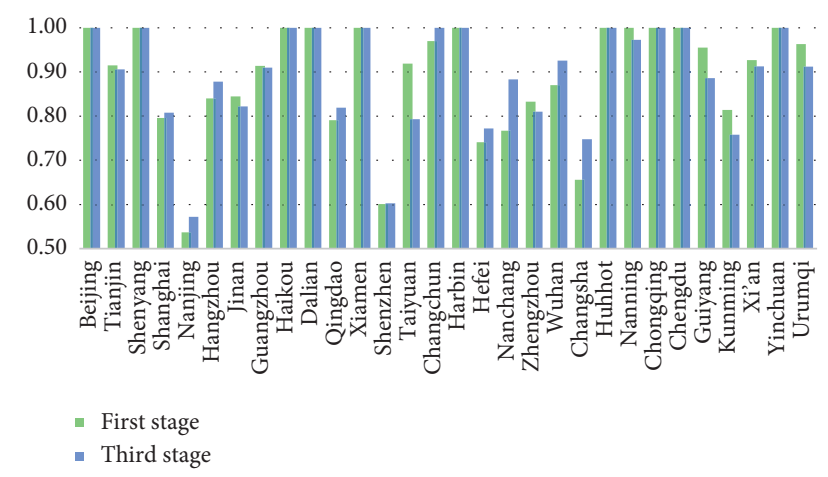

FIgURE 4: Comparison of average pure technical efficiency before and after adjustment (2010-2016).

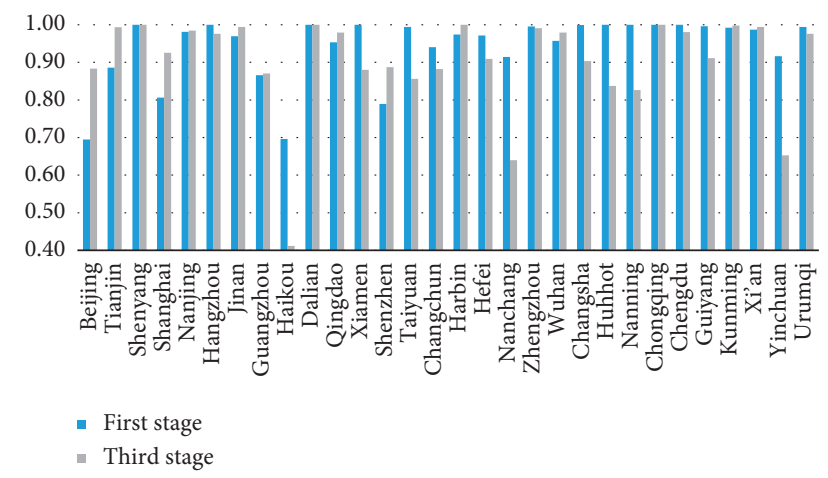

Figure 5: Comparison of average scale efficiency before and after adjustment (2010-2016).

For comparison purposes, Table 5 shows the mean operational efficiency values of the first-stage and the thirdstage analyses. In China, the development environment of bus transport in the three regions (eastern, middle, and western) is obviously different. To explore the regional variations of bus operation efficiency, the three regions are analysed as shown in Table 5 .

In the eastern region, on the whole, the average value of the pure technical efficiency changed slightly (from 0.883 to 0.887 ), while the average scale efficiency increased obviously (from 0.902 to 0.931 ), and thereby the average operation efficiency of bus transport increased from 0.797 to 0.823 . As seen, all of the scale efficiency values are higher than the pure technical efficiency values before and after adjustment. We can conclude that bus transport efficiency is primarily determined by pure technical efficiency in this region. Specifically, the scores of comprehensive efficiency values improved in most cites (10/13). This indicates that exogenous environmental factors have a relatively significant negative impact on public transport operation in this region. In particular, in Nanjing and Shenzhen, the increase in comprehensive efficiency and pure technical efficiency before and after adjustment was extremely low. This implies that the driver of bus transport efficiency improvement is pure technical efficiency promotion in the two cities. Additionally, Haikou's scale efficiency presents the most dramatic decrease, illustrating that external environments are favourable to the development of bus transport in Haikou. Meanwhile, Haikou is in the increasing stage of scale returns, implying that expanding production scale will help to improve operation efficiency.

For the middle region, the mean pure technical efficiency score changed slightly from 0.870 to 0.875 , while the mean scale efficiency decreased from 0.968 to 0.936 , resulting in the fact that the mean operation efficiency of bus transport decreased from 0.841 to 0.817 . After these external environmental factors were excluded, the average efficiency values of five cities decreased, and those of the remaining three cities improved. The average scale efficiency values of seven cities are larger than 0.9 and significantly higher than the average pure technical efficiency. Inversely, the average scale efficiency of Nanchang is far below the average level. Additionally, Table 3 shows that Changchun, Hefei, Zhengzhou, Wuhan, and Changsha have both a high scale efficiency and medium technical efficiency. This suggests that opportunities to improve the operation efficiency of bus transport in this region are mainly based on improving the pure technical efficiency.

In regard to the western region, the average efficiency score of bus transport dropped from 0.912 to 0.872 (7 cities decreased, while 3 cities increased), the average pure technical efficiency decreased slightly from 0.968 to 0.954 , and the average scale efficiency value descended from 0.943 to 0.917 . Most of the cities have both high pure technical efficiency and high-scale efficiency, except Kunming (with low pure technical efficiency) and Yinchuan and Hohhot (with low-scale efficiency). Thus, Kunming should be paid much attention to improving its pure technical efficiency. Conversely, Yinchuan and Hohhot need to expand financial subsidies and increase the production scale to improve the service quality of their bus transport.

\subsection{Influencing Analysis of Exogenous Environment Factors.} To further explore how the external environment variables affect the operation efficiency of bus transport, we employed the tobit model to analyse the data. The dependent variable is the operation efficiency value of the first stage, and the independent variables are the influencing factors. For the purpose of removing the impact of different data dimensions on parameter estimation and judging the influence directly 
TABLE 6: Tobit regression results.

\begin{tabular}{|c|c|c|c|c|}
\hline Variable & Coefficient & Std. Err & t-Statistic & $P>|t|$ \\
\hline Cons & $1.037939^{* * *}$ & 0.120017 & 8.648301 & 0.000000 \\
\hline Population density & -0.027802 & 0.078398 & -0.354630 & 0.726400 \\
\hline GDP per capita & $-0.000003^{* *}$ & 0.000001 & -2.504794 & 0.020600 \\
\hline Number of taxis & $0.000008^{* *}$ & 0.000004 & 2.226554 & 0.037100 \\
\hline Passenger volume of rail transport & $-0.000002^{* * *}$ & 0.000001 & -2.943633 & 0.007800 \\
\hline Car ownership & -0.000678 & 0.000438 & -1.546801 & 0.136800 \\
\hline
\end{tabular}

${ }^{*},{ }^{* *}$, and ${ }^{* * *}$ represent the significance level at $10 \%, 5 \%$, and $1 \%$, respectively.

from the regression coefficient, the variables of selected external environment are first standardized. The tobit model regression was carried out with Eviews 10.0 software. The regression results are presented in Table 6.

From Table 6, we can see that the population density has a negative relationship with the operation efficiency of bus transport, and the regression coefficient fails to pass the significance test, indicating that population density has no noticeable influence effect on the bus transport efficiency. This result is inconsistent with the expectation and with the existing literature $[3,12]$. Population aggregation is the most direct reflection of urban attraction, competitiveness, and economic development. More densely populated cities are also more developed cities. This negative relationship is possibly explained by the argument of the second variable in Table 6.

For the second variable, GDP per capita negatively impacts bus transport efficiency; this relationship is significant. A city with a high GDP per capita value may mean that people in this city have a greater ability to pay. With the continuous growth of the economy, people will pay more attention to speed, comfort, and convenience and not only cost. Compared to private cars, taxi, and rail transit, the satisfaction of bus transport service with respect to convenience, comfort, and speed is undoubtedly the lowest. However, the most prominent advantage of bus transport lies in its low cost. It is difficult for bus transport to satisfy the growing travel demands of people in terms of speed and comfort. Therefore, continuous improvement of service quality is the key to enhancing bus transport efficiency.

Taxi transport is an important component of urban public transportation. Table 5 shows that the number of taxis positively impacts bus transport efficiency, and the relationship is significant. As the most flexible public transport, taxi transport can greatly meet people's convenience travel needs. However, from the perspective of passengers, taxi travel costs are so high that not everyone can afford it. Conversely, the greatest advantage of bus transport is its low travel cost, but the disadvantage of insufficient convenience is also prominent. As a result, in large cities with insufficient bus network density, combined taxis and buses for travel is a reasonable choice for some people. What needs to be illustrated is that with the large-scale launch of shared bicycles, the transfer function of taxi will be gradually replaced by them.

In regard to the fourth factor, we can see that the passenger volume of urban rail transport has a significant negative effect on the operation efficiency of bus transport.
This negative relationship is possibly related to the distinct advantages, such as the speed, punctuality, and capacity, of urban rail transport. Based on the different functions of urban rail transport and bus transport, a public authority should make great efforts to promote the integration of these two modes of transport and maximize the strengths of both of the concerned parties to improve the efficiency values of both modes of transport.

Finally, car ownership negatively impacts bus transport efficiency. The coefficient fails to pass the significance test, implying that car ownership has little impact on public transport efficiency. Private car owners pay more attention to service instead of only travel cost [44]. However, over the past two decades, subsidies have tended to cover the gap between ticket revenues and operating cost to maintain the sustainability of bus transport operations [42], but the improvement in bus service quality is not significant. Modern cities provide people with a variety of travel options, such as taxis, rail transport, and bicycles. Car owners may have had a low dependence on bus transport before they purchased their own cars, which might be an explanation of why the impact of car ownership on bus operation efficiency is not significant. Thus, to enhance bus transport efficiency, great efforts should be taken to improve the service quality of bus transport.

\section{Conclusions and Policy Implications}

5.1. Conclusions. Considering the influence of exogenous factors on bus transport operation, we adopt the three-stage DEA model to evaluate the operation efficiency of bus transport in China during 2010-2016. Then, the tobit model is employed to further explore the impact of exogenous factors on bus transport operation. Through the empirical evaluation of urban bus transport operation efficiency in 30 central cities, the following conclusions can be obtained:

After exogenous environmental factors and random errors are eliminated, the bus operation efficiency values of 30 eastern, middle, and western region cities in China have changed greatly. After adjustment, the national average scale efficiency value has always been higher than the average pure technical efficiency value, and the national average comprehensive efficiency value is consistent with the average pure technical efficiency value in the development level and trend. It can be seen that the exogenous environmental factors and random errors mainly affect the operational efficiency through the scale efficiency factor. The existence of such factors will affect the measurement of the real 
environmental efficiency. Therefore, it is reasonable and necessary to use the three-stage DEA model to evaluate the bus operational efficiency of China's central cities.

In terms of the time series, the real operation efficiency value of these 30 cities decreased from 0.854 in 2010 to 0.801 in 2016. This indicates that the attraction of bus transport was declining. This is contrary to the original intention of the public transport priority policy. This result further suggests that the utilization efficiency of financial funds in bus transport continues to decline. Accordingly, taking effective measures to improve the utilization efficiency of subsidies is the critical task of bus transport development.

There are obvious spatial imbalances in the real bus operation efficiency of the three regions in China. During 2010-2016, the western region had the highest operation efficiency, followed by the eastern and middle regions. The eastern region should pay more attention to the introduction of new technologies and improve the quality of public transport services to improve operational efficiency. Opportunities to improve the operational efficiency of bus transport in the middle region are mainly based on improving the pure technical efficiency. The western region should focus on the expansion of the scale of bus operations.

Based on the tobit regression analysis, we found that GDP, taxi transport, and urban rail transport have significant impacts on the operation efficiency of bus transport. In contrast to expectations, the population density and car ownership fail to pass the significance test, implying that the effects of these two factors are not significant. This finding may be related to the increasing income level and the littlechanged low-service quality of bus transport.

5.2. Policy Implications. From the above results and analysis, several policy recommendations can be proposed as described below.

First, it is found that, against the background of largescale financial investment into bus transport in recent years, the operation efficiency of bus transport has not been substantially improved but has been declining year by year. To avoid enterprises focusing on how to obtain financial subsidies and expand operating scale blindly, improving the mechanism of financial subsidies and promoting the efficiency of financial funds are critical tasks for management. Our further suggestion is that local governments should publish their subsidy data of bus transport to allow for social supervision, which may be more conducive to the improvement of fund efficiency. In light of the important role of service quality in enhancing the attraction of public transport, this paper suggests that service quality assessment should be taken as one of the determining factors of bus transport subsidies.

Second, with the increases in income, the quality of travel service has become the main standard for people when choosing their transport mode. Therefore, the longterm maintenance of low price and little improvement in service quality may lead to the gradual loss of the market share of bus transport. This point is also confirmed by our results that show that bus transport efficiency has declined year by year. From this perspective, it is urgent that bus operators make great efforts to improve service quality in the future. The bus transport network should be further optimized because it is the basis for improving the bus transport service level and competition. At the same time, especially in the super cities in the eastern and middle regions of China, it is important for bus operators to make great efforts to improve at the management level as well as introduce advanced techniques and equipment to fully increase its operational efficiency to encourage people to choose urban bus transport. Additionally, cities with lowscale efficiency should make efforts to greatly expand scale improvement through increasing financial subsidies and expanding production scale.

Third, the different functions of urban rail transport and bus transport determine that they are both competitive and interdependent. The integration of various transport [45] modes is an important developing trend in urban transport [48]. To fully exert their respective advantages, the coordinated development and effective convergence of urban bus transport and urban rail transport must be considered. Accordingly, only when the two systems of urban bus transport and urban rail transport realize the seamless connections for passengers can the operational efficiency of the two systems be promoted together.

This study can be further expanded. To measure the efficiency of as many cities as possible, this paper only selected four input-output variables due to the lack of data for some cities. The greater the number of input-output variables that are considered, the more accurate the obtained efficiency values will be [5]. The number of input-output variables should be increased when the relevant data of all the middle region cities are disclosed. Furthermore, in addition to the five external environmental factors utilized in this study, other factors (such as shared bikes and online car-hailing) should be considered in future research on bus transport systems. We also expect new models to be incorporated in the assessment of bus transport efficiency.

\section{Data Availability}

All data generated or analysed during this study are included in this article.

\section{Conflicts of Interest}

The authors declare no conflicts of interest.

\section{Acknowledgments}

The study was supported by the Social Science Foundation of Shaanxi Province (S2019013), the Special Fund for Basic Scientific Research of Central College of Chang'an University (0009-2014G6234026 and 300102230667), the MOE Layout Foundation of Humanities and Social Sciences (19YJA79009), and Social Science Program of Shanxi Province (2019B117), and Economic and Social Statistics Research Project of Shanxi Province (KY[2019]100). 


\section{References}

[1] M. G. Badami and M. Haider, "An analysis of public bus transit performance in Indian cities," Transportation Research Part A: Policy and Practice, vol. 41, no. 10, pp. 961-981, 2007.

[2] J. Holmgren, "Putting our money to good use: can we attract more passengers without increasing subsidies?" Research in Transportation Economics, vol. 29, no. 1, pp. 256-260, 2010.

[3] H. Fitzová, M. Matulová, and Z. Tomeš, "Determinants of urban public transport efficiency: case study of the Czech republic," European Transport Research Review, vol. 10, no. 2, 2018.

[4] A. Venkatesh and S. Kushwaha, "Short and long-run cost efficiency in Indian public bus companies using data envelopment Analysis," Socio-Economic Planning Sciences, vol. 61, pp. 29-36, 2018.

[5] J. Holmgren, "The effects of using different output measures in efficiency analysis of public transport operations," Research in Transportation Business \& Management, vol. 28, pp. 12-22, 2018.

[6] B. De Borger, K. Kerstens, and Á. Costa, "Public transit performance: what does one learn from frontier studies?" Transport Reviews, vol. 22, no. 1, pp. 1-38, 2002.

[7] J. Odeck, "Congestion, ownership, region of operation, and scale: their impact on bus operator performance in Norway," Socio-Economic Planning Sciences, vol. 40, no. 1, pp. 52-69, 2006.

[8] E. Ottoz, G. Fornengo, and M. Di Giacomo, "The impact of ownership on the cost of bus service provision: an example from Italy," Applied Economics, vol. 41, no. 3, pp. 337-349, 2009.

[9] J.-S. Hahn, D.-K. Kim, H.-C. Kim, and C. Lee, "Efficiency analysis on bus companies in Seoul city using a network DEA model," KSCE Journal of Civil Engineering, vol. 17, no. 6, pp. 1480-1488, 2013.

[10] C.-C. Kang, H. A. Khan, C.-M. Feng, and C.-C. Wu, "Efficiency evaluation of bus transit firms with and without consideration of environmental air-pollution emissions," Transportation Research Part D: Transport and Environment, vol. 50, pp. 505-519, 2017.

[11] C. Sheth, K. Triantis, and D. Teodorović, "Performance evaluation of bus routes: a provider and passenger perspective," Transportation Research Part E: Logistics and Transportation Review, vol. 43, no. 4, pp. 453-478, 2007.

[12] D. Yao, L. Xu, and J. Li, "Evaluating the performance of public transit system: a case study of eleven cities in China," Sustainability, vol. 11, no. 13, p. 3555, 2019.

[13] N. Tian, S. Tang, A. Che, and P. Wu, "Measuring regional transport sustainability using super-efficiency SBM-DEA with weighting preference," Journal of Cleaner Production, vol. 242, p. $118474,2020$.

[14] G. J. Fielding, T. T. Babitsky, and M. E. Brenner, "Performance evaluation for bus transit," Transportation Research Part A: General, vol. 19, no. 1, pp. 73-82, 1985.

[15] C. Daraio, M. Diana, F. Di Costa, C. Leporelli, G. Matteucci, and A. Nastasi, "Efficiency and effectiveness in the urban public transport sector: a critical review with directions for future research," European Journal Of Operational Research, vol. 248, no. 1, pp. 1-20, 2016.

[16] Y.-C. Chiou, L. W. Lan, and B. T. H. Yen, "Route-based data envelopment analysis models," Transportation Research Part E: Logistics and Transportation Review, vol. 48, no. 2, pp. 415-425, 2012.
[17] E. T. J. Lin, L. W. Lan, and A. K. Y. Chiu, "Measuring transport efficiency with adjustment of accidents: case of Taipei bus transit," Transportmetrica, vol. 6, no. 2, pp. 79-96, 2010.

[18] M.-M. Yu and C.-K. Fan, "Measuring the performance of multimode bus transit: a mixed structure network DEA model," Transportation Research Part E: Logistics and Transportation Review, vol. 45, no. 3, pp. 501-515, 2009.

[19] W. Roy and A. Yvrande-Billon, "Ownership, contractual practices and technical efficiency: the case of urban public transport in France," Journal of Transport Economics and Policy, vol. 41, no. 2, pp. 257-282, 2007.

[20] V. Pina and L. Torres, "Analysis of the efficiency of local government services delivery. An application to urban public transport," Transportation Research Part A: Policy and Practice, vol. 35, no. 10, pp. 929-944, 2001.

[21] C. Zhang, Z. Juan, Q. Luo, and G. Xiao, "Performance evaluation of public transit systems using a combined evaluation method," Transport Policy, vol. 45, pp. 156-167, 2016.

[22] M. Filippini, M. Koller, and G. Masiero, "Competitive tendering versus performance-based negotiation in Swiss public transport," Transportation Research Part A: Policy and Practice, vol. 82, pp. 158-168, 2015.

[23] M. G. Karlaftis and D. Tsamboulas, "Efficiency measurement in public transport: are findings specification sensitive?" Transportation Research Part A: Policy and Practice, vol. 46, no. 2, pp. 392-402, 2012.

[24] J. Holmgren, "The efficiency of public transport operations-an evaluation using stochastic frontier analysis," Research in Transportation Economics, vol. 39, no. 1, pp. 50-57, 2013.

[25] A. Charnes, W. W. Cooper, and E. Rhodes, "Measuring the efficiency of decision making units," European Journal of Operational Research, vol. 2, no. 6, pp. 429-444, 1978.

[26] K. Kerstens, "Technical efficiency measurement and explanation of French urban transit companies," Transportation Research Part A: Policy and Practice, vol. 30, no. 6, pp. 431452, 1996.

[27] L.-s. Sun, R. Jian, and F.-t. Ren, "DEA method for evaluating the transfer efficiency of urban public transportation termina," Journal of Beijing University of Technology, vol. 33, pp. 12-18, 2007.

[28] C.-M. Chen, J. Du, J. Huo, and J. Zhu, "Undesirable factors in integer-valued DEA: evaluating the operational efficiencies of city bus systems considering safety records," Decision Support Systems, vol. 54, no. 1, pp. 330-335, 2012.

[29] Y. Hawas, M. Khan, and N. Basu, "Evaluating and enhancing the operational performance of public bus systems using GISbased data envelopment analysis," Journal of Public Transportation, vol. 15, no. 2, pp. 19-44, 2012.

[30] B. Starr McMullen and D.-W. Noh, "Accounting for emissions in the measurement of transit agency efficiency: a directional distance function approach," Transportation Research Part D: Transport and Environment, vol. 12, no. 1, pp. 1-9, 2007.

[31] J. Odeck, "The effect of mergers on efficiency and productivity of public transport services," Transportation Research Part A: Policy and Practice, vol. 42, no. 4, pp. 696-708, 2008.

[32] C.-q. Zhang, J. Zhi-cai, and J. Peng, "Evaluating the efficiency of urban public transit operators using information entropy and SE-DEA combined model," Industrial \& Engineering Chemistry, vol. 20, pp. 146-153, 2015.

[33] H. O. Fried, C. A. K. Lovell, S. S. Schmidt, and S. Yaisawarng, "Accounting for environment effects and statistical noise in data envelopment analysis," Journal of Productivity Analysis, vol. 17, no. 1/2, pp. 157-174, 2002. 
[34] R. D. Banker, A. Charnes, and W. W. Cooper, "Some models for estimating technical and scale inefficiencies in data envelopment analysis," Management Science, vol. 30, no. 9, pp. 1078-1092, 1984.

[35] K. Zhang, Y. Xu, and D. Sun, "A mixed frontier model for urban bus performance evaluation," Proceedings of the Institution of Civil Engineers - Transport, vol. 171, no. 2, pp. 65-74, 2018.

[36] J. Tobin, "Estimation of relationships for limited dependent variables," Econometrica, vol. 26, no. 1, pp. 24-36, 1958.

[37] L. D. Otero, G. Centeno, C. E. Otero, and K. Reeves, "A DEAtobit analysis to understand the role of experience and task factors in the efficiency of software engineers," IEEE Transactions on Engineering Management, vol. 59, no. 3, pp. 391400, 2012.

[38] S. P. Washington, M. G. Karlaftis, and F. Mannering, "Statistical and econometric methods for transportation data analysis," Maritime Economics \& Logistics, vol. 6, no. 2, pp. 187-189, 2004.

[39] D. Sun, Y. Xu, and Z.-R. Peng, "Timetable optimization for single bus line based on hybrid vehicle size model," Journal of Traffic and Transportation Engineering (English Edition), vol. 2, no. 3, pp. 179-186, 2015.

[40] B. D. Taylor, D. Miller, H. Iseki, and C. Fink, "Nature and/or nurture? analyzing the determinants of transit ridership across US urbanized areas," Transportation Research Part A: Policy and Practice, vol. 43, no. 1, pp. 60-77, 2009.

[41] D. Sun, S. Chen, C. Zhang, and S. Shen, "A bus route evaluation model based on GIS and super-efficient data envelopment analysis," Transportation Planning and Technology, vol. 39, no. 4, pp. 407-423, 2016.

[42] D. K. T. Florian Drevs, J. Lindenmeier, and S. Renne, "Crowding-in or crowding out an empirical analysis on the effect of subsidies on individual willingness-to-pay for public transportation. pdf," Transportation Research Part A: Policy and Practice, vol. 59, pp. 250-261, 2019.

[43] S. Jia, C. Wang, Y. Li, F. Zhang, and W. Liu, "The urbanization efficiency in Chengdu city: an estimation based on a threestage DEA model," Physics and Chemistry of the Earth, Parts $A / B / C$, vol. 101, pp. 59-69, 2017.

[44] H. Wang and M. C. Chao, "The impacts of the mass rapid transit system on household car ownership in Taipei," Journal of Sustainable Development of Energy Water \& Environment Systems, vol. 2, pp. 191-207, 2014.

[45] Y. Wang, Z. Yao, C. Wang, J. Ren, and Q. Chen, "The impact of intelligent transportation points system based on Elo rating on emergence of cooperation at $Y$ intersection," Applied Mathematics and Computation, vol. 370, Article ID 124923, 2020. 